\title{
Distance from shore as an indicator of disturbance of gray whales during a seismic survey off Sakhalin Island, Russia
}

\author{
Judy E. Muir ${ }^{1,10, *}$, Laurie Ainsworth ${ }^{2,3}$, Ruth Joy ${ }^{4}$, Roberto Racca ${ }^{5}$, Yury Bychkov ${ }^{1}$, \\ Glenn Gailey ${ }^{6,11}$, Valeriy Vladimirov ${ }^{7}$, Sergei Starodymov ${ }^{8}$, Koen Bröker ${ }^{9}$ \\ ${ }^{1}$ LGL Limited environmental research associates, Sidney, British Columbia V8L 3Y8, Canada \\ ${ }^{2}$ Department of Statistics, Simon Fraser University, Burnaby, British Columbia V5A 1S6, Canada \\ ${ }^{3}$ PhiStat Research \& Consulting, North Vancouver, British Columbia V7J 2Z3, Canada \\ ${ }^{4}$ Department of Statistics \& Actuarial Science, Simon Fraser University, Burnaby, British Columbia V5A 1S6, Canada \\ ${ }^{5}$ JASCO Applied Sciences (Canada) Ltd., Victoria, British Columbia V8Z 7X8, Canada \\ ${ }^{6}$ Marine Mammal Research Program, Texas A\&M University at Galveston, Galveston, TX 77553, USA \\ ${ }^{7}$ Russian Marine Mammal Council, Nakhimovskiy ave. 36, 117218 Moscow, Russia \\ ${ }^{8}$ ExxonMobil Russia Inc., 31 Novinsky b-r 31, 123242 Moscow, Russia \\ ${ }^{9}$ Shell Global Solutions, Lange Kleiweg 40, 2288 GK Rijswijk, The Netherlands \\ ${ }^{10}$ Present address: Muir Ecological Services Ltd., Victoria, British Columbia V8R 4J1, Canada \\ ${ }^{11}$ Present address: Cascadia Research Collective, 218 1/2 W. 4th Ave, Olympia, WA 98501, USA
}

\begin{abstract}
A seismic survey was conducted adjacent to the nearshore feeding ground of gray whales Eschrichtius robustus off northeastern Sakhalin Island, Russia. Scan surveys were conducted at 7 shore stations before, during and after the seismic survey. We investigated whether gray whales shifted their distribution with respect to distance from the shoreline in response to acoustic pulses from the seismic source. To do this, we used linear mixed effects modelling that included effects of detection, space and time. Data were tested for effects of magnitude and presence/absence of sound from seismic activity on whale distance from shore. Sound covariates were estimated over 3 temporal scales ( $8 \mathrm{~h}, 3 \mathrm{~d}$ and since the start of seismic activity) at locations 500 and $5000 \mathrm{~m}$ offshore each observation station. Sighting distance from shore was less in poor visibility and at earlier times of day. No significant effects of sound were identified, although data suggest that at most stations, sighting distance from shore increased slightly over the $2 \mathrm{wk}$ of the seismic survey. The analysis was limited, however, by several factors that included low numbers of sightings throughout most of the study, non-availability of data on biomass of gray whale prey and sources of error that could not be accounted for in the model. Sensitivity to potential errors in sighting distance estimation was assessed using a correction factor based on known locations of vessels and gray whales when sighted. The model was refitted using distance-corrected sightings. Results were consistent with the original model.
\end{abstract}

KEY WORDS: Gray whale - Eschrichtius robustus - Seismic survey · Spatio-temporal analysis · Sighting distance $\cdot$ Anthropogenic disturbance $\cdot$ Cumulative sound exposure $\cdot$ Distance correction factor

\section{INTRODUCTION}

Marine mammals are highly dependent on sound for communication, navigation, predator avoidance, social interactions and foraging (e.g. Southall et al.

${ }^{*}$ Corresponding author: jemuir@telus.net
2007). Underwater sound from human activities can have adverse effects such as hearing injury, masking of important sounds and behavioural disturbance that ranges from minor behavioural changes to avoidance of a sound source and displacement from

() The authors 2015. Open Access under Creative Commons by Attribution Licence. Use, distribution and reproduction are unrestricted. Authors and original publication must be credited. 
an area (Richardson et al. 1995, Nowacek et al. 2007). Offshore oil and gas exploration and production occur in many parts of the world in both nearshore and deep water marine environments, and can generate substantial amounts of low-frequency noise (Hildebrand 2009). This can be continuous noise from platform and pipeline construction, dredging, drilling and vessel traffic, or pulsed sounds from airguns used in geophysical surveys to map hydrocarbon reservoirs. Numerous studies have documented avoidance of an active airgun sound source by cetaceans (reviewed in Richardson et al. 1995, Gordon et al. 2003, Nowacek et al. 2007). Evidence of response includes lower sighting rates and increased sighting distances from a seismic vessel when airguns are firing, and observations of individual animals moving away from the sound source. For example, Malme et al. (1986) found that $10 \%$ of gray whales Eschrichtius robustus stopped feeding and moved away from an airgun source at received sound levels of $163 \mathrm{~dB}$ re $1 \mu \mathrm{Pa}$ root mean square (rms).

Sakhalin Energy Investment Company Ltd. (hereafter Sakhalin Energy) conducted a repeat 3-D seismic survey from 17 June-2 July 2010 on the northeastern Sakhalin shelf, Russia, to map changes in oil and gas reservoirs in the company's PiltunAstokh (PA) license area. The seismic survey area was located offshore of an important nearshore ('Piltun') feeding area for gray whales. Sakhalin Energy and the IUCN Western Gray Whale Advisory Panel (hereafter WGWAP) jointly developed a mitigation and monitoring program (MMP) for the seismic survey (Bröker et al. 2015, this Theme Section). To minimize impacts on gray whales, the survey was planned to start as soon as ice melt occurred, when whales begin to move into the feeding area and their numbers are typically low. While the standard practice of establishing a safety radius (often termed 'exclusion zone') around the seismic source to prevent auditory injury to the whales was followed, the MMP was also designed to mitigate behavioural disturbance within the Piltun feeding area (Bröker et al. 2015, this Theme Section).

The Piltun feeding area is approximately $120 \mathrm{~km}$ long and $10 \mathrm{~km}$ wide, extending from the shore to approximately the $20 \mathrm{~m}$ depth contour. The preferred prey of gray whales in the Piltun feeding area are epibenthic amphipods (primarily Monoporeia affinis), but isopods, bivalve molluscs, polychaetes and sand lance Ammodytes hexapterus are also eaten (Fadeev 2013). High prey biomasses have been consistently documented at water depths of 5 to $15 \mathrm{~m}$ that are typically within $5 \mathrm{~km}$ of shore (Fadeev 2013).
Shore-based gray whale surveys were planned to be conducted before, during and after seismic activity to monitor gray whale distribution and abundance in the southern part of the feeding area closest to the seismic survey area. We conducted 2 spatio-temporal analyses to assess the potential effects of exposure to sound from seismic activity on gray whale distribution, and, by extension, the effectiveness of the MMP. One study used $1 \mathrm{~km}^{2}$ gray whale density surfaces to assess whether exposure to sound from the seismic source was associated with a population-level displacement of whales within the monitored feeding area (Muir et al. in press, this Theme Section). The second analysis, presented here, investigated whether a population-level shift occurred in whale distribution with respect to distance from the shoreline in response to either the presence/absence of acoustic pulses or the magnitude of the cumulative sound exposure level (CSEL) from the seismic source.

We estimated sound covariates at locations 500 and $5000 \mathrm{~m}$ offshore each observation station; these locations were inshore and offshore, respectively, of the core distribution of gray whales within the feeding area as documented by field research since 1997. Behavioural responses of marine mammals to noise are highly variable and can be affected by factors such as an individual's age, sex and activity state, habituation and the spatial context of exposure such as the location of the sound source relative to that of the animal (Wartzok et al. 2003, Tyack 2009).

Gailey (2008) found that distances to sightings of gray whales in the Sakhalin study area were consistently underestimated by observers using binoculars compared to distances measured using a theodolite. Negative bias in distance estimates using reticle binoculars has also been reported for shipboard surveys (Kinzey \& Gerrodette 2003, Williams et al. 2007, Leaper et al. 2010). To address these biases, we developed a correction factor for errors in distance estimation by the reticle binoculars used during shore-based surveys. This correction factor was used to test the sensitivity of the analyses to potential errors in estimates of sighting locations (i.e. distances from shore).

\section{MATERIALS AND METHODS}

\section{Seismic survey area and execution}

The seismic survey was conducted in a $\sim 170 \mathrm{~km}^{2}$ seismic survey area that was centered on the Molikpaq (hereafter 'PA-A') platform (Fig. 1). The survey area was $\sim 10-25 \mathrm{~km}$ from shore in water $\sim 25-40 \mathrm{~m}$ 
Fig. 1. The seismic survey area (green polygon) with Distribution Stns 9-13 (black triangles) and behaviour Seismic North and Seismic South (purple circles) observation stations shown. Temporary Distribution Stn 9, which was only used while access to Stn 9 was blocked by snow during the first few days of survey effort, is also shown. The 500 and $5000 \mathrm{~m}$ locations at which sound covariates were calculated offshore each distribution and behaviour observation station are illustrated (orange circles). Estimated 20 and $50 \mathrm{~m}$ bathymetry contours are shown as dotted light blue and solid dark blue lines, respectively

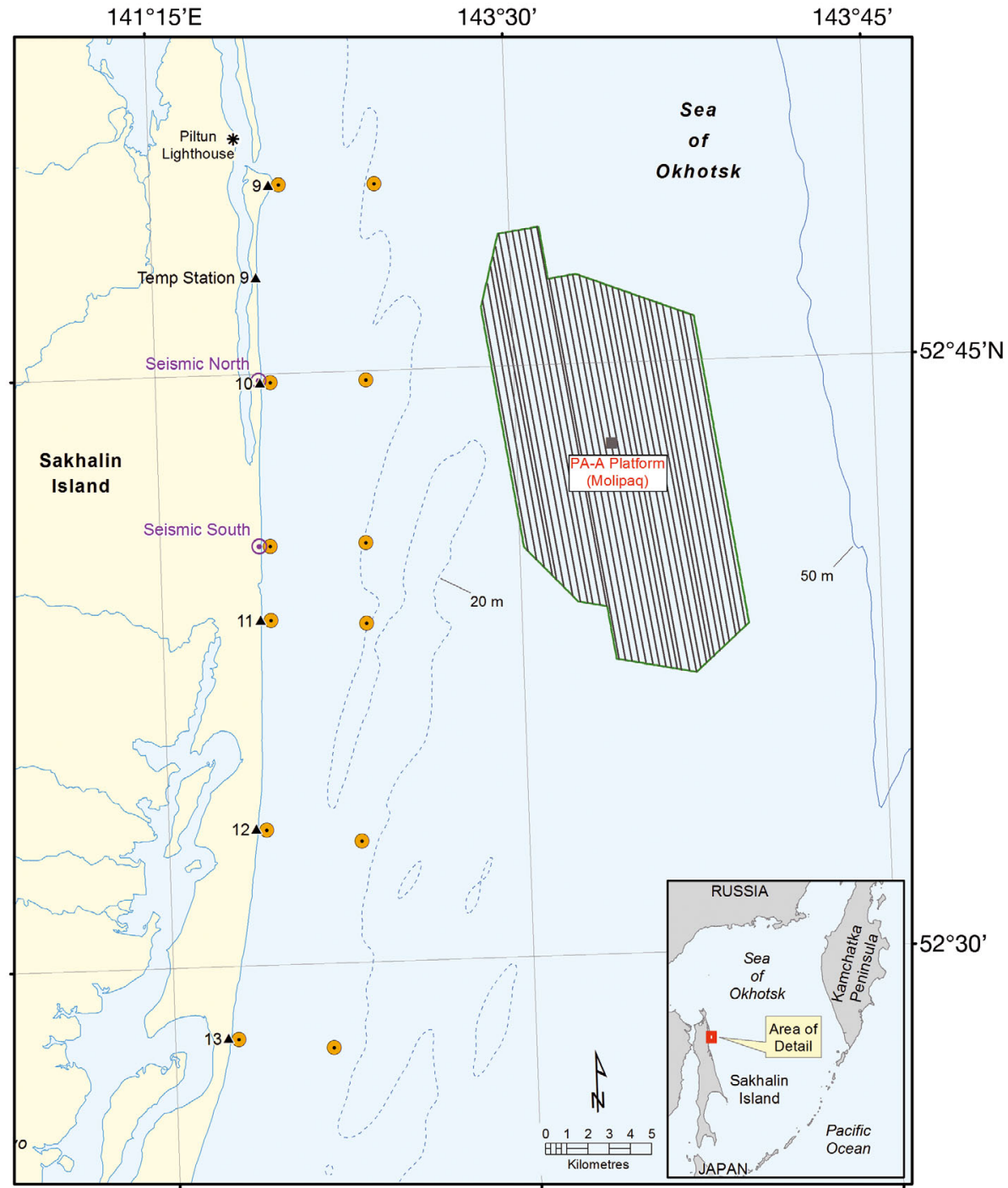

deep. The seabed in this area has a gentle slope with uneven relief (LGL 2010). The substrate consists of fine, sandy soils at water depths up to $\sim 15 \mathrm{~m}$, then transitions to medium- and coarse-grained sand with patches of gravel-pebble soils at 15-35 m water depths (Fadeev 2013).

The seismic vessel sailed along 35 pre-defined lines spaced $\sim 300 \mathrm{~m}$ apart. Each line required $\sim 2 \mathrm{~h}$ to complete at an average speed of 5 knots $\left(9.3 \mathrm{~km} \mathrm{~h}^{-1}\right)$. The vessel towed two $2620 \mathrm{in}^{3}\left(42900 \mathrm{~cm}^{3}\right)$ airgun arrays that each consisted of 27 airguns configured in a flip-flop (alternate firing) mode. Airguns were fired at $\sim 8 \mathrm{~s}$ intervals to generate acoustic pulses that travelled into the sea bottom, passed through strata with different reflective properties, and returned to the surface to be captured by hydrophones towed behind the vessel. The airgun array was shut down during turns (duration ca. $4 \mathrm{~h}$ ) between lines. Longer periods between seismic line sailings occurred in the first few days of the survey due to adverse weather conditions and technical difficulties. A 20 min search for marine mammals was conducted prior to a $20 \mathrm{~min}$ ramp-up procedure before sailing the next line. Further details can be found in Bröker et al. (2015).

\section{Study design and survey protocols}

The design of the shore-based scan surveys from Vladimirov et al. (2010) was adapted for this study to support more intensive daily survey effort. Two 'distribution' teams conducted scans at 5 previously established observation stations located along $\sim 50 \mathrm{~km}$ of coast adjacent to the southern portion of the Piltun feeding area (Fig. 1). A temporary station $\sim 4.5 \mathrm{~km}$ south of Distribution Stn 9 was used for the first few days of monitoring because the road to Stn 9 was blocked by snow. Two 'behaviour' teams conducted 
scans in addition to theodolite tracking and focal animal follows at 2 onshore observation stations, Seismic North (SN) and Seismic South (SS), established specifically for the MMP and located near Distribution Stns 10 and 11, respectively (Fig. 1). Behaviour observers conducted hourly scan surveys unless the team was conducting a focal follow and theodolite tracking on an individual gray whale at the scheduled scan time.

The distribution teams jointly conducted a 'survey' of their 5 stations in $\sim 2 \mathrm{~h}$. This allowed each survey to be timed to coincide with the sailing of a seismic line when airguns were being fired and the subsequent line turn when airguns were silenced. Visual survey effort was evenly spread throughout the day, weather permitting, during the 2 wk prior to seismic activity (pre-seismic) and $2 \mathrm{wk}$ after seismic activity (postseismic). Each team conducted scans at either the 2 northern or 2 southern stations, with both teams conducting a synchronized scan at Distribution Stn 11 on each survey, weather and time permitting (Fig. 2). The 2 distribution teams rotated effort at pairs of northern and southern observation stations on successive surveys to control for observer bias.

Fujinon FMTRC-SX $7 \times 50$ binoculars were used to conduct a continuous scan covering an approximate $180^{\circ}$ area of the nearshore waters at a constant rate $\left(10^{\circ} \mathrm{min}^{-1}\right.$ : distribution teams; $9.3^{\circ} \mathrm{min}^{-1}$ : behaviour teams). All cetacean observations were recorded

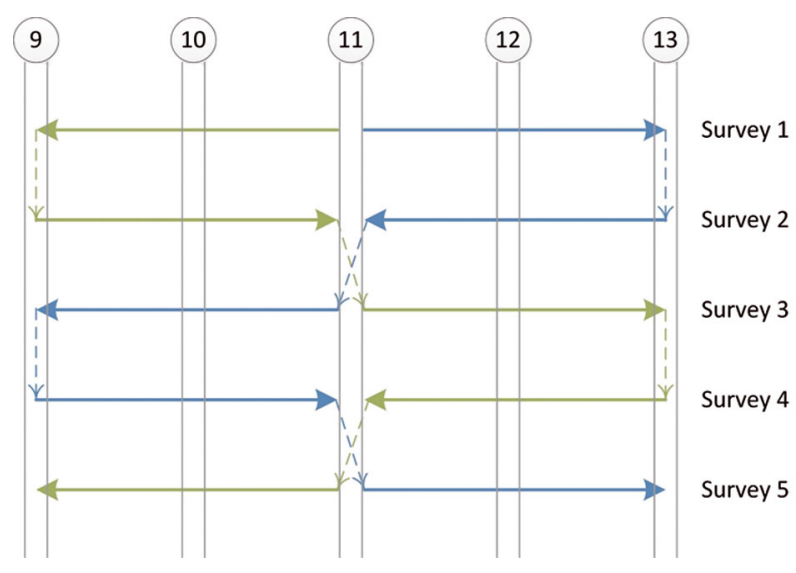

Fig. 2. Survey pattern used to conduct scans at the 5 distribution stations by the 2 teams. Team 1 is shown in green; Team 2 is shown in blue. The teams began Survey 1 by conducting a synchronized scan at Stn 11 . Team 1 then travelled north and conducted scans at Stn 10, followed by Stn 9 . Team 2 travelled south and conducted scans at Stns 12 and 13. The pattern was reversed for Survey 2. Note that teams crossed over and continued travelling in the same direction for the next survey after completing a survey at Stn 11 with sighting time measured to the nearest minute, sighting magnetic bearing and reticle estimate, and number of animals. Sightings of seismic survey and support vessels were also noted. Environmental conditions at an observation station (Beaufort wind force scale [hereafter Beaufort Scale]), visibility, wind speed and direction, presence and location of glare, temperature, pressure and swell height) were documented for each scan. Kestrel 4500 hand-held weather stations were used to measure temperature, pressure, wind speed and wind direction. Visibility was categorized as a 4 level code: 1 - excellent conditions with clear horizon line, 2-good conditions with little to no haze and/or rain with relatively clear horizon line, 3 - fair with some haze and/or rain but horizon still visible enough for reticle estimation, $4-$ poor, no visible horizon due to fog and/or rain. Scan surveys were not conducted if the visibility code was 4, Beaufort Scale exceeded 3, or wind speed exceeded $10.0 \mathrm{~m} \mathrm{~s}^{-1}$. Details of the 2010 distribution and behaviour monitoring protocols are provided in Vladimirov et al. (2011a) and Gailey et al. (2011a), respectively.

\section{Data preparation and mapping}

The distance to each sighting was estimated from the recorded reticle using Lerczak \& Hobbs's (1998) distance approximation equation combined with Leaper \& Gordon's (2001) refraction correction. Each sighting's recorded magnetic bearing was corrected for local magnetic declination $\left(-11.68^{\circ}\right)$ and used with the estimated sighting distance to determine sighting position latitude and longitude.

Duplicate sightings made during synchronized scans at Stn 11 were identified post-survey based on timing and position, similarity in reticle and bearing measurements, and number of individuals. Pairs of duplicate sightings were reduced to a single sighting for analyses by averaging each sighting's latitude and longitude. The maximum number of reported individuals in the duplicated sighting was retained.

Sighting locations were imported into ArcGIS v10.0 (ESRI 2010). We used the ArcGIS Near tool to calculate a perpendicular distance from shore for each sighting.

\section{Synchronized scans}

Duplicate sightings during synchronized scans were used to verify that estimates of sighting loca- 
tions and measurements of survey environmental conditions were comparable between the 2 teams. We also used synchronized scan gray whale sightings to estimate the shore-based detection function using mark-recapture distance sampling (MRDS) methods (Laake \& Borchers 2004). This analysis was conducted using the package mrds in R v3.1.1 ( $\mathrm{R}$ Development Core Team 2014). Detailed methods for the MRDS analysis are provided in Supplement 1 at www.int-res.com/articles/suppl/n029p161_supp.pdf.

\section{Distance correction factor}

Gray whale sightings made by behaviour teams during the seismic survey monitoring and earlier studies (Gailey et al. 2007b, 2008, 2009, 2010, 2011b) were used to assess errors in the estimation of gray whale sighting distance by reticle binoculars in nearshore waters. The 'true' distance to each gray whale sighting was accurately measured using a theodolite (Würsig et al. 1991, Gailey \& Ortega-Ortiz 2002), while the distance to that sighting was simultaneously estimated using reticle binoculars. Only sightings within $\sim 5 \mathrm{~km}$ distance of an observation station were measured, to minimize inaccuracies in theodolite distance estimation, given the relatively low elevations of the stations.

Sightings of the seismic survey environmental monitoring vessel 'Pavel Gordienko' made during scans by both distribution and behaviour teams provided comparisons of estimated versus 'true' distances farther offshore. Each vessel sighting time was matched to the closest position in time to the 'Pavel Gordienko' GPS and automatic identification system (AIS) tracks. Sightings were only retained for analysis if matched times were within $1 \mathrm{~min}$ to minimize discrepancies in estimated and actual vessel positions. ArcGISv10 (ESRI 2010) was used to calculate the 'true' distance and bearing from the observation station to the matched vessel's track position. Vessel sightings with estimated 'true' distances beyond the horizon or with a difference of $>5^{\circ}$ between the scan's estimated and 'true' bearing to a sighting were excluded from the analysis.

Linear regressions of paired estimated and 'true' sighting distances were conducted to determine a correction factor. Data were log transformed prior to modelling. Separate regressions were conducted for zero reticle and non-zero reticle sightings that appeared to have different biases in distance estimation.

\section{Sound covariates}

We assessed acoustic effects from seismic activity at 3 temporal scales by accumulating sound exposure over 3 time windows: moderately short $(8 \mathrm{~h})$, moderately long ( $3 \mathrm{~d}$ ) and since the start of seismic survey activity. Sound covariates were calculated using estimated median sound exposure level (SEL) over depth for individual seismic pulses and did not include contributions of non-pulse sound energy from other sources. Sound covariates were estimated at each of 2 points located 500 and $5000 \mathrm{~m}$ offshore of each observation station (Fig. 1). These sound covariate locations (SCLs) provided estimates of sound accumulations inshore and offshore of typical gray whale distribution at each observation station within the southern Piltun feeding area.

Sound covariates for the 3 time windows of $8 \mathrm{~h}$ (cSEL8h), $3 \mathrm{~d}$ (cSEL3d) and since the start of seismic activity (cSELss) were calculated for each scan that was conducted at a station. A scan's sound covariates were accumulated at the 500 and $5000 \mathrm{~m} \mathrm{SCLs}$ for the scan's station over each time window preceding that scan's midpoint time. Sound covariates were estimated by numerically modelling the seismic source pulse level and directivity properties of the seismic airgun array source and the sound propagation in the region. The propagation model (Austin \& Chapman 2011) took into account the bathymetry and the acoustic properties of the water column and sub-bottom substrates in which the acoustic energy could travel. This modelling was based on the same set of underlying parameters that were selected in the field for each individual seismic line to ensure an agreement within $3 \mathrm{~dB}$ between model estimates and real-time measurements at an array of acoustic sensors positioned along the defined feeding area boundary (Muir et al. 2015, Racca et al. 2015, both this Theme Section).

\section{Statistical model}

We conducted a regression analysis to test the magnitude of cSEL estimated at the 500 and $5000 \mathrm{~m}$ SCLs and the presence/absence of sound within the 3 time windows ( $8 \mathrm{~h}, 3 \mathrm{~d}$ and since start of seismic) on gray whale sighting distance from shore. We used a linear mixed effects (LME) model framework (Zuur et al. 2010) that allowed inclusion of both fixed and random effects, and specifications for the error structure when variance assumptions were violated due to heteroscedasticity or autocorrelation. Random effects 
provide flexibility to accommodate induced covariance structure and are useful for analyzing longitudinal data, repeated measurements and block designs (Pinheiro \& Bates 2000). Six sightings (7 gray whales) were excluded due to missing covariate values, resulting in a total of 436 sightings for analyses. Few gray whales were seen at the most southerly station (Stn 13); these sightings were pooled with those from Stn 12 for model development. Sightings from the $2 \mathrm{~d}$ of effort at Temporary Stn 9 were combined with those from the adjacent Stn 9.

The basic LME model is (Zuur et al. 2010):

$$
\begin{gathered}
Y_{i}=\mathbf{X}_{i} \beta+\mathbf{Z}_{i} b_{i}+\varepsilon_{i} \\
b_{i} \sim N(0, D) \\
\varepsilon_{i} \sim N(0, \Sigma)
\end{gathered}
$$

where $b_{i}$ are normally distributed random effects associated with the $i^{\text {th }}$ station having a mean of 0 and variance of $\mathbf{D}, \varepsilon_{i}$ is a vector of normally distributed residual errors with a mean of zero and variance of $\Sigma_{i}, b_{i}$ and $\varepsilon_{i}$ are independent, $i=1,2, \ldots N, N$ is the number of stations. $\mathbf{X}_{i}$ is the design matrix for the fixed covariates and $\mathbf{Z}_{i}$ is the design matrix for the random covariates. The response variable, $Y_{i}$ is the sighting distance from shore. $Y_{i r} b_{i r}$ and $\varepsilon_{i}$ are vectors of length $n_{i}$, where $n_{i}$ is the number of sightings at Stn $i$.

All statistical modelling was performed using R v2.15.2 (R Development Core Team 2012). LME models were fitted using the $\mathrm{R}$ package 'nmle'. Sighting distances were right skewed and thus were log transformed to make them normally distributed prior to analysis. The fixed effects covariates, $\mathbf{X}$, included environmental covariates that could affect detection (e.g. visibility, Beaufort Scale), those associated with space/ time variation in whale locations (e.g. station, date) and seismic sound covariates (Table 1). A random effect for station was included to account for correlation among repeated measurements at a station. The model also included a term for heteroscedasticity across stations.

Models were developed using a staged approach that (a) determined the random effects structure ('base model'), (b) fitted detection covariates to the base model, (c) fitted state covariates to the base model, (d) determined the best combination of detection and state covariates ('base covariate model') and (e) added sound covariates to the base covariate model. Highly correlated sound covariates were not entered into the same model to avoid collinearity. Following Zuur et al. (2010), we included as many fixed effects as possible when assessing random effects. Restricted maximum likelihood (REML) and maximum likelihood (MLE) were used to fit random effects and fixed effects, respectively. Covariate effects were tested using likelihood ratio tests between LME models with and without the covariate term(s). Due to the large number of covariates tested, we chose a Type I error (alpha) of 0.01 to reduce experiment-wise error. Akaike Information Criteria (AICs) and likelihood ratio tests were used to select the best candidate model at each stage of model development.
Table 1. Covariates used in the distance from shore model. Note that although

\begin{tabular}{|c|c|c|c|}
\hline Variable & $\begin{array}{l}\text { Effect } \\
\text { type }\end{array}$ & $\begin{array}{l}\text { Covariate } \\
\text { type }\end{array}$ & Description \\
\hline Station & Random & State & Observation station identifier \\
\hline Day & Fixed & State & $\begin{array}{l}\text { Day (since start of scan survey effort) } \\
\text { of sighting; Day } 1=6 \text { June } 2010\end{array}$ \\
\hline Time of day & Fixed & State & $\begin{array}{l}\text { Time of day (midpoint time of scan) } \\
\text { of sighting }\end{array}$ \\
\hline Tide height & Fixed & State & $\begin{array}{l}\text { Predicted tide height }(\mathrm{m}) \text { at observa- } \\
\text { tion station during scan }\end{array}$ \\
\hline Visibility & Fixed & Detection & $\begin{array}{l}\text { Visibility code: categorical with } 3 \\
\text { levels }(1,2,3 \text { with } 1 \text { as the } \\
\text { reference category) }\end{array}$ \\
\hline Sea state & Fixed & Detection & $\begin{array}{l}\text { Beaufort scale: categorical with } 4 \\
\text { levels }(0,1,2,3 \text { with } 0 \text { as the } \\
\text { reference category) }\end{array}$ \\
\hline Swell & Fixed & Detection & Swell height in metres \\
\hline Wind direction & Fixed & Detection & Wind direction in degrees \\
\hline Glare & Fixed & Detection & $\begin{array}{l}\text { Percent of scan area obscured by } \\
\text { glare }\end{array}$ \\
\hline $\begin{array}{l}\text { CSEL8h500m, } \\
\text { cSEL8h5000m }\end{array}$ & Fixed & Seismic & $\begin{array}{l}\text { Cumulative SEL over an } 8 \mathrm{~h} \text { time } \\
\text { window at a } 500 \text { or } 5000 \mathrm{~m} \text { point } \\
\text { offshore each observation station }\end{array}$ \\
\hline $\begin{array}{l}\text { CSEL3d500m, } \\
\text { cSEL3d5000m }\end{array}$ & Fixed & Seismic & $\begin{array}{l}\text { Cumulative SEL over a } 3 \text { d time } \\
\text { window at a } 500 \text { or } 5000 \text { m point } \\
\text { offshore each observation station }\end{array}$ \\
\hline $\begin{array}{l}\text { cSELss500m, } \\
\text { cSELss5000m }\end{array}$ & Fixed & Seismic & $\begin{array}{l}\text { Cumulative SEL since the start of } \\
\text { seismic activity at a } 500 \text { or } 5000 \mathrm{~m} \\
\text { point offshore each observation } \\
\text { station }\end{array}$ \\
\hline Sound8h & Fixed & Seismic & Binary indicator for the presence or \\
\hline Soundss & & & $\begin{array}{l}3 \mathrm{~d} \text { time window or since the start } \\
\text { of seismic activity }\end{array}$ \\
\hline
\end{tabular}
air temperature data were collected, temperature was not used as a covariate in the statistical model. SEL: sound exposure level 
Glare and wind direction were not collected for some scans; therefore, the 'base covariate model' was first determined without these covariates. Effects of glare and wind direction were then assessed using data subsets created for each covariate. The 'base covariate model' was refit to each data subset, and the likelihood ratio test was used to compare the 'base covariate model' to the 'base covariate model' with the subset covariate added.

\section{Sensitivity tests}

Regression models were developed using sighting distances to shore. A sighting represents a single observation of either an individual gray whale or a group of gray whales. We conducted 2 sensitivity tests on the final model. The first test assessed whether using a response of distance from shore for individual whales, as opposed to whale groups, changed model results. We converted sightings to observations of individual gray whales by replicating each sighting record for the number of individuals in that sighting's group. For example, if a sighting was of 2 individuals, then 2 records for individual gray whales were created that had the same distance from shore and associated covariates as the original record. The model was refitted using the individual gray whales' sighting distances, and results were compared.

The second sensitivity test investigated whether potential errors in sighting distances estimated by reticle binoculars affected our findings. We used the modelled distance correction factor to re-estimate gray whale sighting locations. The sighting distances from shore were recalculated, and distancecorrected sightings and individual gray whale data sets were produced. The final models for each of the uncorrected sightings and individual whales were refitted to the corresponding corrected data set, and results were compared.

\section{RESULTS}

The distribution and behaviour teams arrived in the field on 4 June and 1 June, respectively. The seismic survey began on 17 June and was completed on 2 July. Both distribution and behaviour scan surveys provided considerable, although irregular, survey effort during the approximately 2 wk preceding the seismic survey (pre-seismic monitoring) and during the survey. Poor weather, mainly fog, resulted in little effort during the planned 2 wk post-seismic monitoring period (3-14 July). A total of 458 scans that recorded 442 sightings of 544 gray whales were performed throughout the $6 \mathrm{wk}$ monitoring period (Tables 2 \& 3, Figs. S2-S18 in Supplement 2 at www.int-res.com/articles/suppl/n029p161_supp.pdf). Most scans were conducted in the second week of the seismic activity period. Average daily counts of whale sightings per scan at each station showed an increasing trend in numbers throughout the monitoring period (Fig. 3). Sighting distance from shore at each observation station was generally greater during seismic activity compared to pre-seismic,

Table 2. Survey effort (number of scans), the number of gray whale (Eschrichtius robustus) sightings ( $n_{\mathrm{s}}$ ) and total individuals $\left(n_{\mathrm{i}}\right)$ observed at each station for the distribution teams for each week ('dates') of the pre-seismic, seismic and post-seismic monitoring periods. Effort and sightings at temporary Stn 9 (4-10 June) are pooled with Stn 9. Synchronized scans at Stn 11 are reported as single scans, with duplicated sightings reduced to a single sighting. The number of days with at least 1 full scan is given in parentheses after the dates. As Stn 13 was inaccessible until 13 June, a 'full' survey prior to 13 June 2010 included only the other 4 stations. The height $(\mathrm{m})$ is shown in parentheses following each station name. NA indicates not applicable due to no survey effort during that week

\begin{tabular}{|c|c|c|c|c|c|c|c|c|c|c|c|c|}
\hline \multirow{2}{*}{$\begin{array}{l}\text { Period } \\
\text { Dates }\end{array}$} & \multicolumn{2}{|c|}{ Stn $9(4.4)$} & \multicolumn{2}{|c|}{ Stn $10(5.2)$} & \multicolumn{2}{|c|}{ Stn $11(7.0)$} & \multicolumn{2}{|c|}{ Stn $12(9.0)$} & \multicolumn{2}{|c|}{ Stn $13(7.3)$} & \multirow{2}{*}{$\begin{array}{r}\text { Total } \\
\text { scans }\end{array}$} & \multirow{2}{*}{$\begin{array}{c}\text { Total } \\
n_{\mathrm{s}}\left(n_{\mathrm{i}}\right)\end{array}$} \\
\hline & Scans & $n_{\mathrm{s}}\left(n_{\mathrm{i}}\right)$ & Scans & $n_{\mathrm{s}}\left(n_{\mathrm{i}}\right)$ & Scans & $n_{\mathrm{s}}\left(n_{\mathrm{i}}\right)$ & Scans & $n_{\mathrm{s}}\left(n_{\mathrm{i}}\right)$ & Scans & $n_{\mathrm{s}}\left(n_{\mathrm{i}}\right)$ & & \\
\hline \multicolumn{13}{|l|}{ Pre-seismic } \\
\hline 4-10 Jun (3) & 4 & $2(3)$ & 3 & $1(1)$ & 5 & $2(2)$ & 5 & $4(5)$ & NA & NA & 17 & $9(11)$ \\
\hline 11-16 Jun (3) & 11 & $3(3)$ & 11 & $2(2)$ & 12 & $5(7)$ & 12 & $3(4)$ & 3 & $1(1)$ & 49 & $14(17)$ \\
\hline \multicolumn{13}{|l|}{ Seismic } \\
\hline 17-24 Jun (4) & 13 & $14(20)$ & 12 & $9(10)$ & 11 & $8(9)$ & 12 & $6(6)$ & 13 & $2(2)$ & 61 & $39(47)$ \\
\hline 25 Jun-2 Jul (6) & 24 & $120(156)$ & 26 & $43(47)$ & 26 & $29(31)$ & 23 & $18(24)$ & 20 & $8(10)$ & 119 & $218(268)$ \\
\hline \multicolumn{13}{|l|}{ Post-seismic } \\
\hline 3-9 Jul (0) & 0 & $0(0)$ & 0 & $0(0)$ & 0 & $0(0)$ & 0 & $0(0)$ & 0 & $0(0)$ & 0 & $0(0)$ \\
\hline 10-14 Jul (2) & 4 & $14(16)$ & 4 & $5(6)$ & 3 & $3(3)$ & 4 & $1(1)$ & 3 & $1(1)$ & 18 & $24(27)$ \\
\hline Grand total & 56 & 153 (198) & 56 & $60(66)$ & 57 & $47(52)$ & 56 & $32(40)$ & 39 & $12(14)$ & 264 & $304(370)$ \\
\hline
\end{tabular}


Table 3. Survey effort (days, scans), the number of gray whale (Eschrichtius robustus) sightings $\left(n_{\mathrm{s}}\right)$ and total individuals $\left(n_{\mathrm{i}}\right)$ observed at each station for the behaviour teams is shown for each week ('dates') of the pre-seismic, seismic and post-seismic monitoring periods. There was no effort at the Seismic South station in the post-seismic periods. The number of possible survey days is given in parentheses after the dates. The height $(\mathrm{m})$ is shown in parentheses following each station name. NA indicates not applicable due to no survey effort during that week

\begin{tabular}{|c|c|c|c|c|c|c|c|c|}
\hline \multirow{2}{*}{$\begin{array}{l}\text { Period } \\
\text { Dates }\end{array}$} & \multicolumn{3}{|c|}{ Seismic North (7.8) } & \multicolumn{3}{|c|}{ Seismic South (8.5) } & \multirow{2}{*}{$\begin{array}{c}\text { Total } \\
\text { scans }\end{array}$} & \multirow{2}{*}{$\begin{array}{c}\text { Total } \\
n_{\mathrm{s}}\left(n_{\mathrm{i}}\right)\end{array}$} \\
\hline & Days & Scans & s $n_{\mathrm{s}}\left(n_{\mathrm{i}}\right)$ & Days & Scans & $n_{\mathrm{s}}\left(n_{\mathrm{i}}\right)$ & & \\
\hline \multicolumn{9}{|l|}{ Pre-seismic } \\
\hline 4-10 Jun (7) & 5 & 18 & $14(16)$ & 4 & 16 & $3(3)$ & 34 & 17 (19) \\
\hline 11-16 Jun (6) & 3 & 23 & $5(6)$ & 3 & 20 & $6(10)$ & 43 & $11(16)$ \\
\hline \multicolumn{9}{|l|}{ Seismic } \\
\hline 17-24 Jun (8) & 3 & 19 & $10(11)$ & 4 & 26 & 11 (13) & 45 & $21(24)$ \\
\hline 25 Jun-2 Jul (8) & 6 & 40 & $59(80)$ & 4 & 25 & $18(22)$ & 65 & $77(102)$ \\
\hline \multicolumn{9}{|l|}{ Post-seismic } \\
\hline 3-9 Jul (7) & 0 & 0 & 0 & NA & NA & NA & 0 & $0(0)$ \\
\hline 10-14 Jul (5) & 2 & 7 & $12(13)$ & NA & NA & NA & 7 & $12(13)$ \\
\hline Grand total & 19 & 107 & $100(126)$ & 15 & 87 & $38(48)$ & 194 & $138(174)$ \\
\hline
\end{tabular}

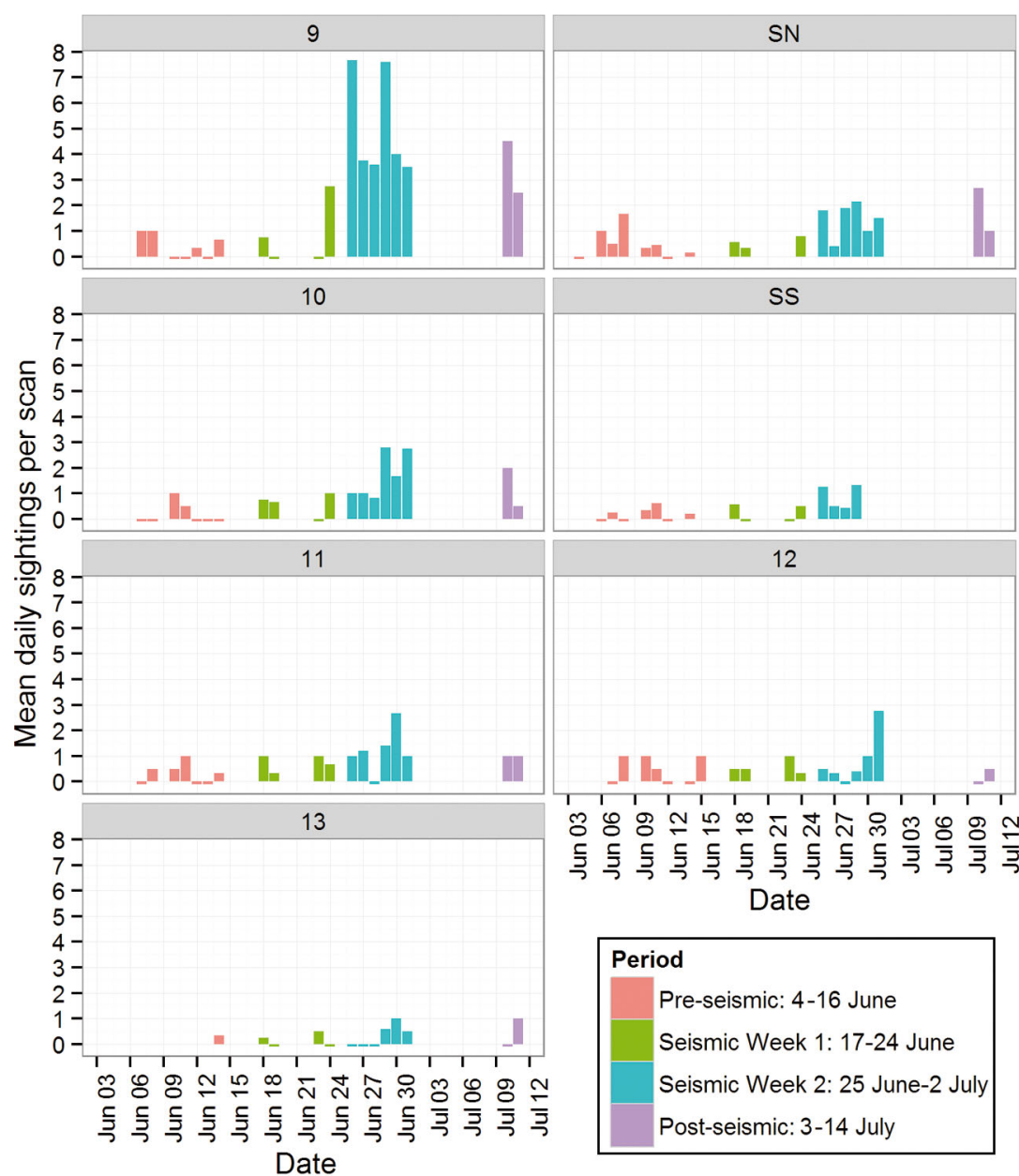

Fig. 3. Average daily number of gray whale (Eschrichtius robustus) sightings per scan at each station over time. Stns 9-13; SN: Seismic North behaviour station; SS: Seismic South behaviour station (see Fig. 1 for station locations).

Days without bars indicate no effort at an observation station although Stn 10 showed the reverse pattern (Fig. 4). Inconsistent patterns were seen when sighting distances from shore during seismic activity were compared with post-seismic; this may be due to the low effort that was possible during the post-seismic period.

\section{Distribution teams' survey effort and gray whale sightings}

Temporary Stn 9 was used for $2 d_{\text {; }}$ 1 scan was conducted at this station on each of 7 and 8 June. Stn 13 was inaccessible until 13 June due to blockage by an impassable stream that forms seasonally. Distribution teams were able to scan all 5 stations during a survey (4 stations until 13 June) at least once on 6, 10 and $2 \mathrm{~d}$ of the pre-seismic, seismic and postseismic monitoring periods, respectively (Table 2). Surveys could not be conducted due to poor environmental conditions (rain, fog, or high winds) on $6 \mathrm{~d}$ during the pre-seismic monitoring, $4 \mathrm{~d}$ during seismic activity and all but $2 \mathrm{~d}$ of the post-seismic period.

\section{Behaviour teams' survey effort and gray whale sightings}

Behaviour teams conducted scans on most days during the first week of pre-seismic monitoring, but effort was only possible on $\sim 50 \%$ of the days during the second week of the pre-seismic and first week of seismic monitoring due to poor weather (Table 3). Visual survey conditions improved during the second week of the seismic survey activity. Only the SN team worked during post-seismic monitoring, and only a few scans could be conducted due to poor survey conditions. As with the distribution scans, few sightings were made in the pre-seismic and post-seismic periods. 


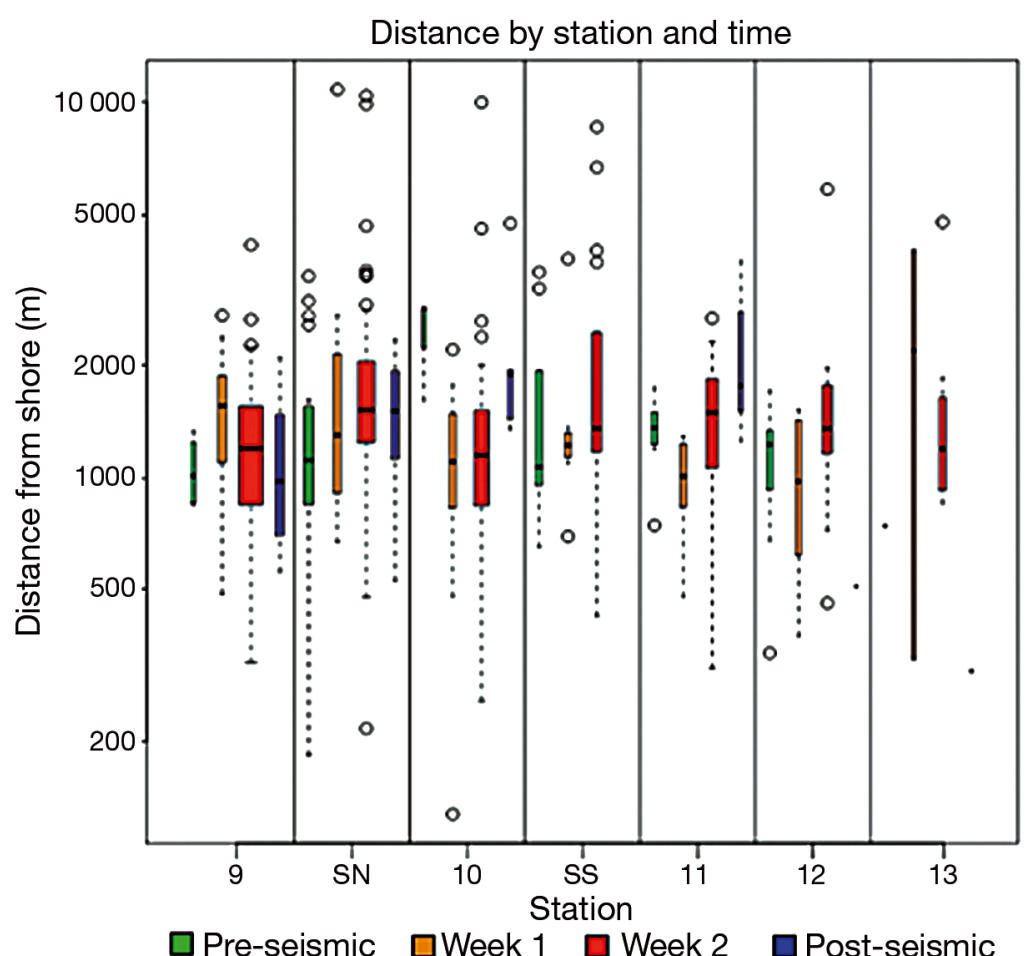

Fig. 4. Gray whale (Eschrichtius robustus) sighting distance from shore by station during the pre-seismic (green), the first half of seismic activity (orange: 17-24 June), the second half of seismic activity (red: 25 June-2 July) and the post-seismic periods (blue). SN: Seismic North behaviour station; SS: Seismic South behaviour station. There was no effort at SS during the post-seismic period. The width of the box indicates sample size (see Tables $2 \& 3$ ). Stations are shown in geographic order from north to south. The box shows the interquartile range (IQR), with the median value indicated by a horizontal line within the box. The whiskers (dotted lines) extend out to the smallest (largest) value within 1.5 times the IQR from the first (third) quartile. Outliers are shown as open circles. Sightings at Stns 12 and 13 were pooled for analysis, due to the small number of sightings at Stn 13

\section{Synchronized scans}

Forty synchronized scans were conducted at Stn 11 with a total of 74 gray whale sightings recorded by both teams. Seventy sightings were matched postsurvey to identify 35 pairs of duplicate observations, of which $80 \%$ had reticle and bearing values within 1 unit of each other. No obvious patterns of increasing measurement error in duplicate sightings were seen with deteriorating visibility, increased sea state, or swell height. Group size estimates were identical for 34 duplicate sightings and differed by 1 whale for the remaining duplicate. The teams recorded the same measurements for visibility code, percent glare, sea state and swell an average of $84 \%$ of the time (range: $80-88 \%$ ). However, only an average of $33 \%$ (range: $18-53 \%$ ) of recorded values for wind speed, wind direction and temperature matched. The wind was gusty, which may have accounted for differences in wind speed and wind direction measurements. Differences in measured temperatures were noted in the field and may have been due to whether measurements were made in the sun or in the shade; protocols were revised to measure temperature in the shade. Each team missed 2 sightings recorded by the other team. The MRDS analysis found that increasing swell height slightly decreased detection probability. No effects on detection probability by sighting distance or environmental conditions of visibility, Beaufort Scale, glare, or wind speed were found. Detailed results for the MRDS analysis are provided in Supplement 1.

\section{Distance correction factor}

A total of 125 vessel and 91 gray whale sightings were used in this analysis. True distances ranged from approximately 4.2 to $12.4 \mathrm{~km}$ for vessel sightings, and $350 \mathrm{~m}$ to $5.2 \mathrm{~km}$ for gray whale sightings. Sighting distances estimated by reticles had a nonlinear bias (Fig. 5). Distances to 51 vessel sightings at 0 reticles (true distances approximately $5.5-12.4 \mathrm{~km}$ ) were generally overestimated, while most distances to the remaining 165 vessel and gray whale sightings at 5.5 to 0.1 reticles (true distances approximately $0.4-11.7 \mathrm{~km}$ ) were underestimated. There was less bias in distance estimation when the true sighting distance was within approximately $1.3 \mathrm{~km}$ of the observation station. The linear regression model for the non-zero reticle sightings provided a good fit $\left(\mathrm{R}^{2}=0.88\right)$ to the log-transformed data. However, the zero reticle regression model fit poorly $\left(\mathrm{R}^{2}=0.30\right)$ (Table 4, Fig. 5).

\section{Sound covariates}

There were 56 periods of airgun firing from 17 June to 2 July 2010. The highest cSELs were at the $5000 \mathrm{~m}$ SCLs offshore the SN and SS behaviour stations and Distribution Stns 10 and 11. The lowest cSELs were in the far south of the study area at both the 500 and $5000 \mathrm{~m}$ cSELs of Distribution Stns 12 and 13 (Fig. 6). The cSELs for each time window were greater at the $5000 \mathrm{~m}$ compared to the $500 \mathrm{~m}$ SCL at each station. Strong correlations ( $\mathrm{r}>0.85$ ) were 

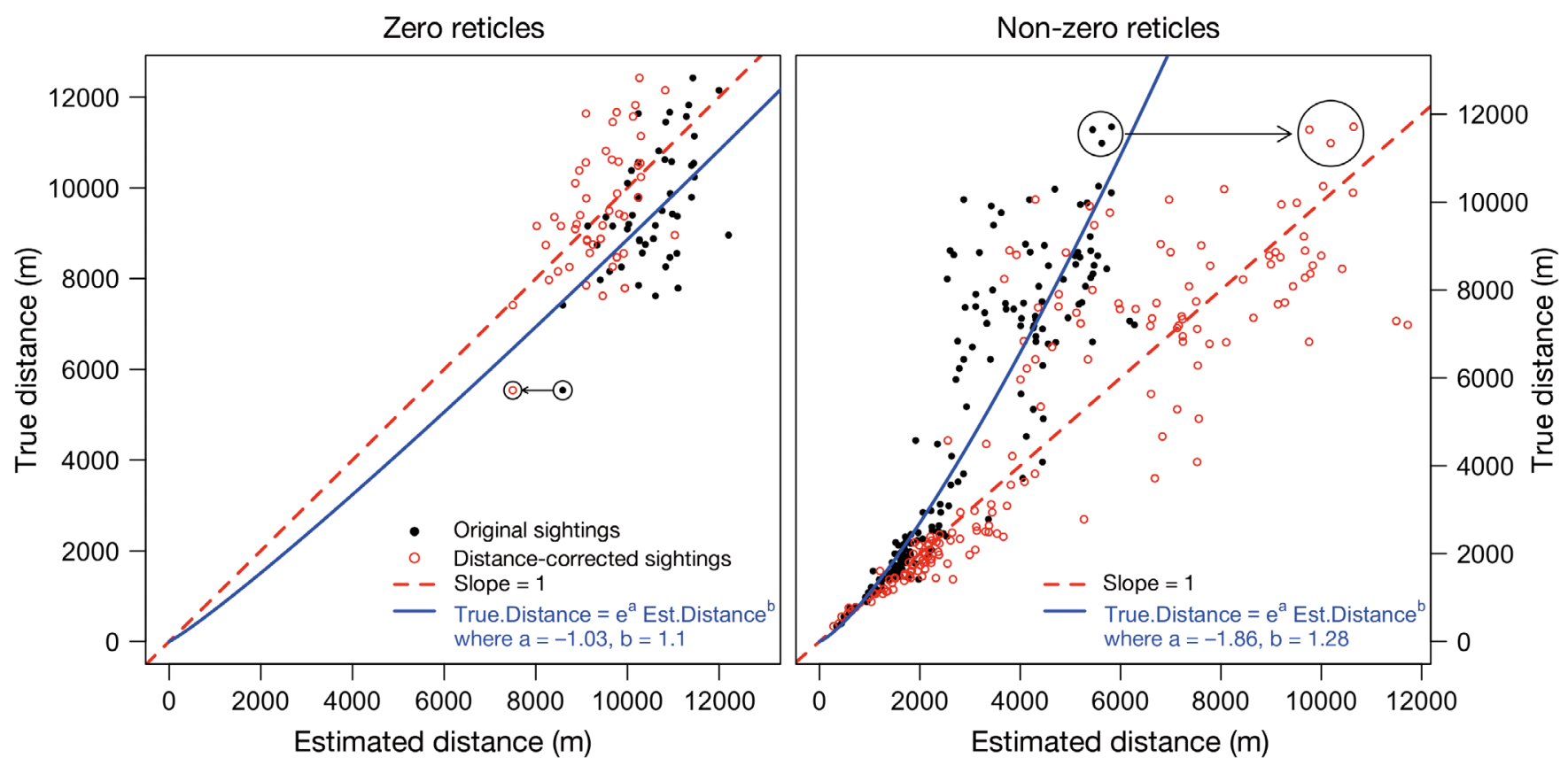

Fig. 5. Correcting the zero (left panel) and non-zero (right panel) reticle gray whale sightings. Each panel illustrates the estimated distance ( $x$-axis) vs. the true (measured) distance (y-axis) for each sighting; both original sightings (small black dots) and distance-corrected sightings (red open circles) are shown. One zero and 3 non-zero reticle data points are circled and shown before and after applying the correction factor using the model equation shown in the panel (blue text, using intercept and slope values in Table 4. A regression line is provided for each model (blue line). The 1:1 line is shown for reference (red dashed line)

found among seismic sound covariates for different time windows at each SCL, and within a sound accumulation period at the 500 and $5000 \mathrm{~m}$ SCLs for a scan at a given station.

\section{Statistical model}

The 'base model' included random effects to account for repeated measurements at each station and differences in variability across stations. As noted above, covariates were assessed by a likelihood ratio test with a type-I error rate of 0.01 . Of the detection covariates, only visibility, which indicated sighting distance decreased as visibility deteriorated, was retained (likelihood ratio test, $\mathrm{p}<0.005$ ). Although the model with visibility and swell had a slightly

Table 4. Results for the zero reticle and non-zero reticle distance correction factor regression models. ${ }^{*} p<0.001$

\begin{tabular}{|lcccc|}
\hline Regression model & $\begin{array}{c}\text { No. of } \\
\text { pairs }\end{array}$ & Intercept & Slope & $\mathrm{R}^{2}$ \\
\hline Non-zero reticle pairs & 165 & $-1.856^{*}$ & $1.284^{*}$ & 0.88 \\
Zero reticle pairs & 51 & $\begin{array}{c}-1.030, \\
(\mathrm{p}=0.642)\end{array}$ & $1.099^{*}$ & 0.30 \\
& \multicolumn{5}{|c}{} \\
\hline
\end{tabular}

smaller AIC, the likelihood ratio test showed this was not a significant improvement $(p=0.13)$ (Tables 5 $\& 6)$. The number of days from the beginning of scan survey effort (6 June 2010) did not improve AIC values (Table 5). Time of day and tide height each slightly improved model fit. Time of day, that was positively associated with sighting distance from shore, provided the best improvement and had a significant log-likelihood test $(p<0.005)$. The 'base covariate model' thus included time of day and visibility (Tables 5 \& 6). Glare did not improve the AIC value when added to the 'base covariate model' in the glare data subset. Although the 'base covariate model' with wind direction evidenced a slight decrease in AIC, the likelihood ratio test showed this was not a significant improvement $(p=0.14)$. None of the sound covariates (on/off indicator or magnitude of sound exposure from the seismic source) for each combination of SCLs and time windows improved model AICs when entered separately or when combined with the base covariate model (Tables 5 \& 7). The final model therefore included a random effect for station, a term for heterogeneity, visibility and time of day (Table 8).

The final model's marginal $\mathrm{R}^{2}$ value that describes the proportion of variance explained through the fixed factors alone (Nakagawa \& Schielzeth 2013) 


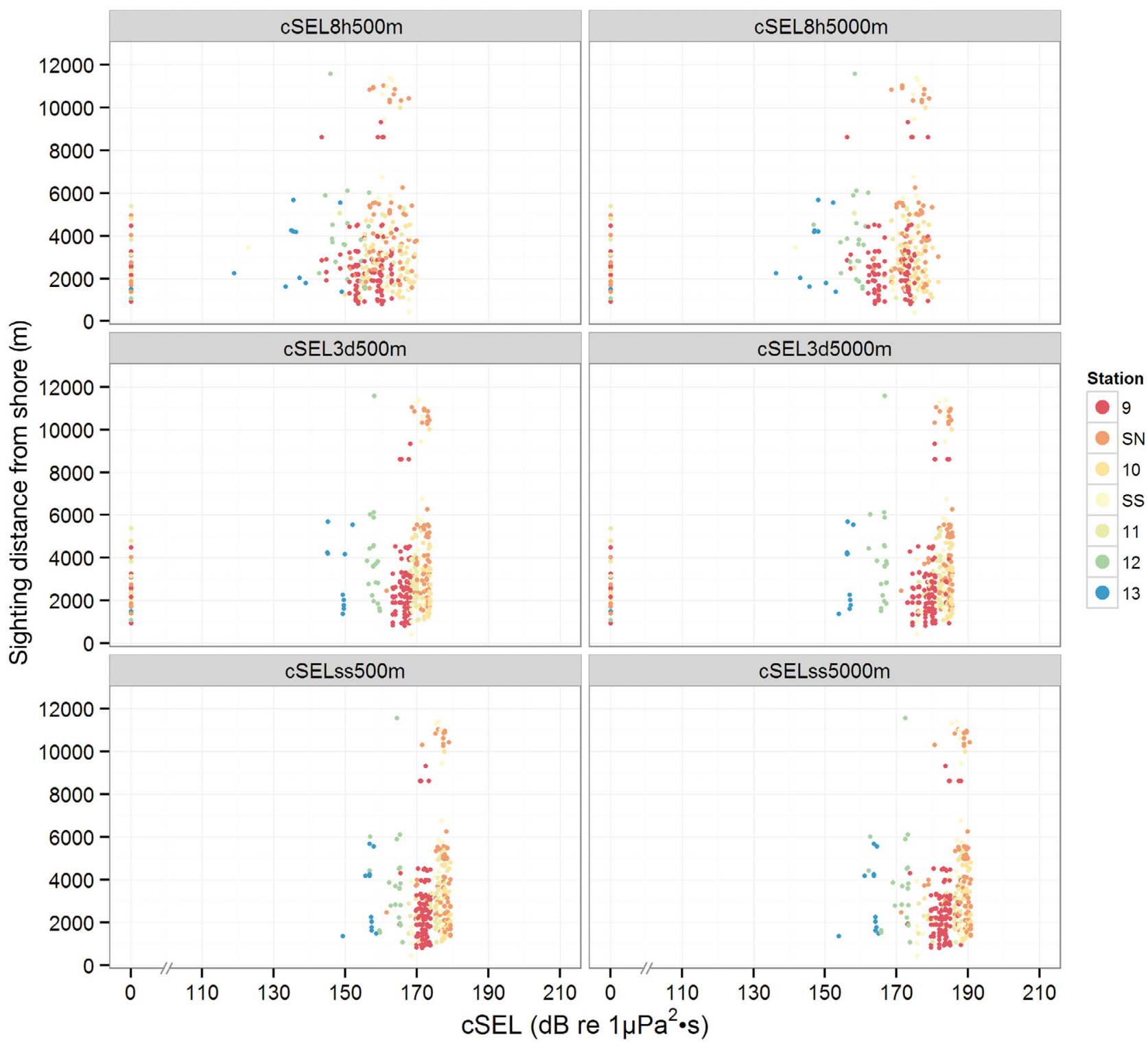

Fig. 6. Sound covariate cumulative sound exposure levels (cSEL, in $\mathrm{dB}$ ) from the seismic survey source calculated over the $8 \mathrm{~h}$, $3 \mathrm{~d}$ and since the start of seismic activity (ss) periods used in the analysis. Sound covariate values were calculated at the 500 and $5000 \mathrm{~m}$ points offshore of each observation station. Sound accumulation levels at Distribution Stns 9-13 and the 2 behaviour stations (SN: Seismic North; SS: Seismic South) are shown in the colour key

was 0.08 , indicating poor model predictions. Residuals (Fig. 7) showed large distances were underestimated and small distances were overestimated. Residuals also showed the model predicted poorly at Stn 10 where sighting distances closer to shore had been observed during periods of 'on' compared to 'off' sound (median 'on' distance: $1.13 \mathrm{~km}$; median 'off' distance: $1.92 \mathrm{~km}$ ), which was the opposite pattern to other stations (median 'on' distance: $1.32 \mathrm{~km}$; median 'off' distance: $1.20 \mathrm{~km}$ ) (Fig. 8). We added an interaction between the $8 \mathrm{~h}$ sound on/off indicator and Stn 10 to the final model to isolate the effect of on versus off sound for this outlier station. Significant terms in the revised model included visibility, time of day and the interaction between the $8 \mathrm{~h}$ sound on/off indicator and Stn 10. While the revised model had a lower AIC, the log-likelihood test was not significant using our experiment-wise alpha of $0.01(p=0.046)$.

\section{Sensitivity tests}

All models selected in the sensitivity tests were consistent with the uncorrected sightings model in 
Table 5. Model covariate Akaike's information criterion (AIC) values. The base model includes a random effect for station and accounts for heterogeneity across stations. Detection and state covariates were added to the base model. Sound covariates were assessed using the 'base covariate model' created by adding retained covariates of visibility and time to the base model. SEL: sound exposure level; see Table 1 for further explanations

\begin{tabular}{|lrr|}
\hline Model & df & AIC \\
\hline 'Base model' & 8 & 755.90 \\
Base model + Visibility & 10 & 742.28 \\
Base model + Seastate & 9 & 756.40 \\
Base model + Swell & 9 & 756.33 \\
Base model + Visibility + Seastate & 11 & 743.74 \\
Base model + Visibility + Swell & 11 & 742.02 \\
Base model + Visibility + Seastate + Swell & 12 & 743.22 \\
Base model + Day & 9 & 756.94 \\
Base model + Time of day & 9 & 749.31 \\
Base model + Tide height & 9 & 752.29 \\
Base model + Time of day + Tide height & 10 & 751.30 \\
Base model + Visibility + Time of day = & 11 & 738.76 \\
'Base covariate model' & 12 & 740.75 \\
Base covariate model + Sound8h & 12 & 740.76 \\
Base covariate model + Sound3d & 12 & 740.44 \\
Base covariate model + Soundss & 13 & 742.75 \\
Base covariate model + cSEL8h500m + Sound8h & 13 & 742.26 \\
Base covariate model + cSEL3d500m + Sound3d & 13 & 741.67 \\
Base covariate model + cSELss500m + Soundss & 13 & 742.75 \\
Base covariate model + cSEL8h5000m + Sound8h & 13 & 742.43 \\
Base covariate model + cSEL3d5000m+ Sound3d & 13 & 741.82 \\
Base covariate model + cSELss5000m + Soundss & & \\
\hline
\end{tabular}

that no effects of sound exposure covariates were found. Effects of visibility were also similar and substantially contributed to explaining variation in gray whale distance from shore. Time effects were retained in most models, although the sensitivity test for individual (uncorrected) whales resulted in a similar, albeit more significant, time effect. The time effect decreased for both the sightings and individual distance corrected models, and was no longer significant for the sightings model (likelihood ratio test, $\mathrm{p}=$ $0.08)$.

\section{DISCUSSION}

This study investigated whether gray whales in a nearshore feeding area showed a population-level shift in their distribution with respect to shore in response to the presence/ absence of acoustic pulses or the magnitude of the CSEL from seismic survey airguns. We found no effects of sound, although our data sug- gested that, with the exception of Stn 10, sighting distance from shore at most observation stations increased slightly during the 2 wk seismic survey compared to before and after the survey. Sample sizes were sufficient to determine that sighting distance from shore decreased in poor visibility and at earlier times of day. Our analysis of sound effects was limited, however, by several factors that included low numbers of sightings throughout most of our study, unavailability of gray whale prey biomass data and sources of error that were not accounted for in the model.

The primary mitigation measure of the seismic survey, i.e. conducting the survey as early in the season as possible, meant that few gray whales were in the feeding area until the second week of the seismic survey. This limited sample sizes during seismic activity and reduced statistical power to detect effects of the magnitude of cumulative sound. Analyzing effects of presence ('on') versus absence ('off') of sound was largely restricted to comparing sightings during the seismic survey to pre-/post-seismic monitoring, because the sound covariate time window lengths resulted in few periods of 'off' sound during the seismic survey. Statistical power to detect an on/off effect was limited because the combination of few whales present during pre-seismic monitoring and poor weather that severely curtailed survey effort during the post-seismic monitoring resulted in low 'off' sample sizes.

Gray whales switch among feeding sites and prey species to maximize foraging efficiency and energy intake (Nerini 1984, Dunham \& Duffus 2001, 2002). Their benthic and epibenthic prey in the Piltun feeding area have a patchy spatial distribution, and locations of high biomass vary across years (Fadeev 2013). Gray whales also have a top-down effect on their prey supply (Coyle et al. 2007) and thus exhaust localized patches with a high prey biomass. Consequently, gray whales likely would have been shifting
Table 6. Log-likelihood (LogLik) tests used in model selection. AIC: Akaike's information criterion. L. ratio: likelihood ratio statistic

\begin{tabular}{|lrrrrrr|}
\hline Model & df & AIC & LogLik & Test & L. ratio & p-value \\
\hline 1. Base model & 8.00 & 755.90 & -369.95 & & & \\
2. Visibility & 10.00 & 742.28 & -361.14 & 1 vs. 2 & 17.63 & $<0.005$ \\
3. Visibility + Swell & 11.00 & 742.02 & -360.01 & 2 vs. 3 & 2.26 & 0.13 \\
4. Time of day & 9.00 & 749.31 & -365.66 & 1 vs. 4 & 8.59 & $<0.005$ \\
5. Visibility + Time of day & 11.00 & 738.76 & -358.38 & 4 vs. 5 & 14.55 & $<0.005$ \\
\hline
\end{tabular}




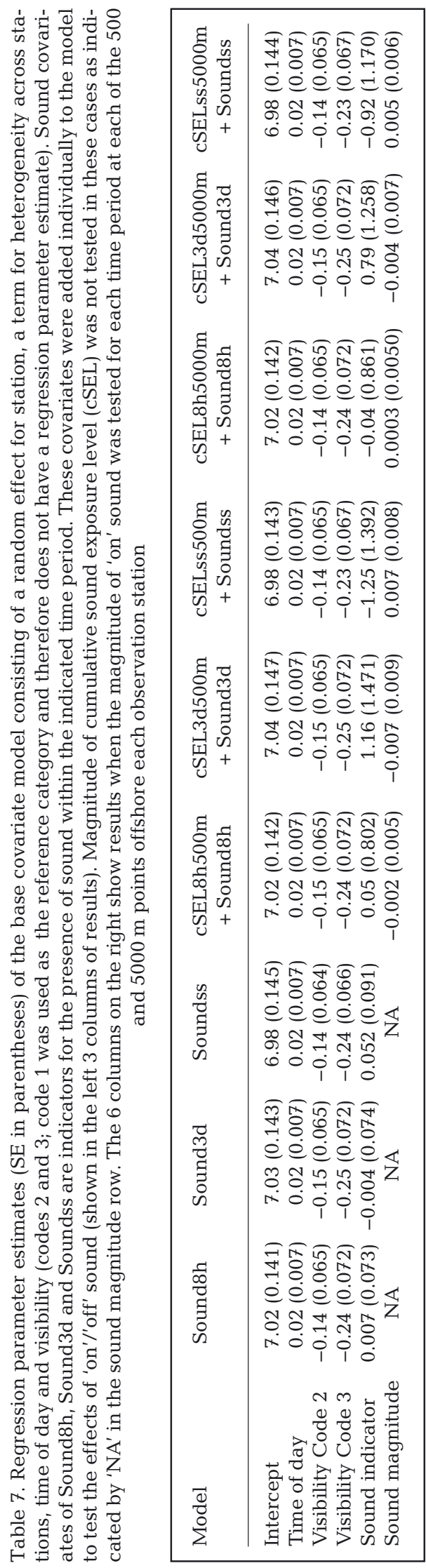

Table 8. Distance from shore model fit for the final model that included a random effect for station and a term for heterogeneity across stations. 'Value' is the regression parameter estimate for the model intercept and the retained covariates of Time of day, and categorical Visibility Code (code 1 was used as the reference category and therefore does not have a regression parameter estimate). Degrees of freedom $=427$

\begin{tabular}{|lrc|}
\hline & Value & SE \\
\hline Intercept & 7.025 & 0.1180 \\
Time of day & 0.016 & 0.0068 \\
Visibility Code 2 & -0.146 & 0.0643 \\
Visibility Code 3 & -0.250 & 0.0652 \\
\hline
\end{tabular}

their distribution during the time of our study, independent of any effects of sound, which would have reduced the predictive ability of the model and confounded our ability to assess the effects of sound.

Sources of error in our model included uncertainty in estimated sound covariate values and in calculated sighting distances from shore. We attempted to limit errors in estimated sound covariates by using model parameters that were selected in the field for each individual seismic line to ensure an agreement within $3 \mathrm{~dB}$ between model estimates and real-time measurements. However, our covariates were estimated at different locations than those used for the real-time model verification, and thus may have shown greater error than the $3 \mathrm{~dB}$ threshold.

\section{Sighting distance estimation}

Errors in calculated sighting distances from shore may have arisen due to errors in estimation of radial sighting distance from an observation station. Distance estimation using reticle binoculars relies on closely lining up the top reticle in the binoculars with the horizon. This can be difficult when the horizon is unclear during poor visibility, and could contribute to errors in estimated distances. Additional error could have been introduced by using predicted tide heights when accounting for observer elevation at the time of the sighting. In addition, studies have found a negative bias in sighting distances estimated from reticles (e.g. Kinzey \& Gerrodette 2003, Williams et al. 2007, Leaper et al. 2010). We refit our sound effects model using sightings with estimated distances recalculated using our modelled correction factor. The 2 models were similar, suggesting that errors in sighting distance estimation by reticle binoculars did not affect results of our analyses. However, we had some difficulties and limitations in 

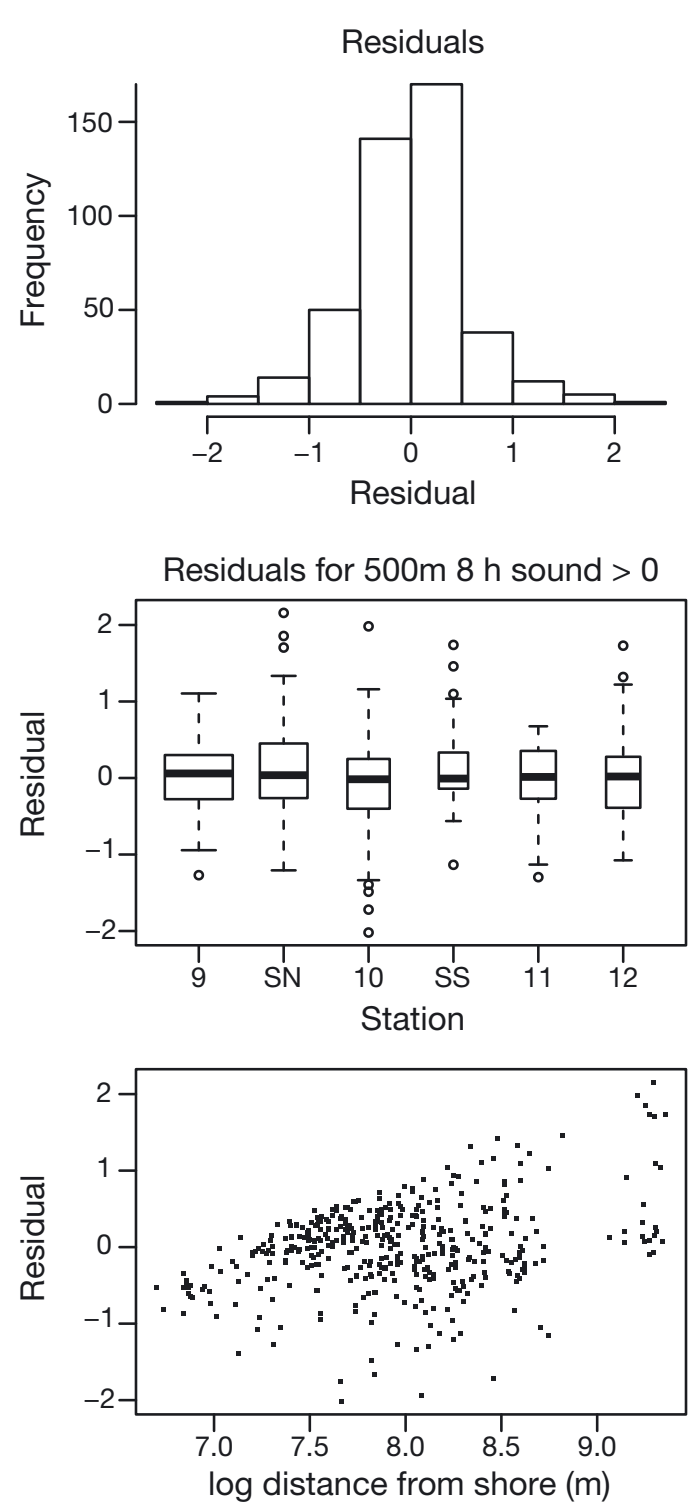

developing the distance correction model. Zero reticle sightings were modelled separately because these had a positive bias in distance estimation, whereas the remaining reticle values had a negative bias. This difference in bias may be explained by the fact that reticle estimation can only be rounded up to zero reticles, and not rounded down as for the other reticles. The zero reticle distance correction model fit poorly, which could be due to the clumping of data points for the single reticle value used in the model. The sightings at greater distances that were used to develop our correction factor were all of vessels. Williams et al. (2007) found that bias in distance estimation depended on whether the object of the cue was a fixed, continuously visible object or something ephemeral such as a whale blow. It would be benefi-
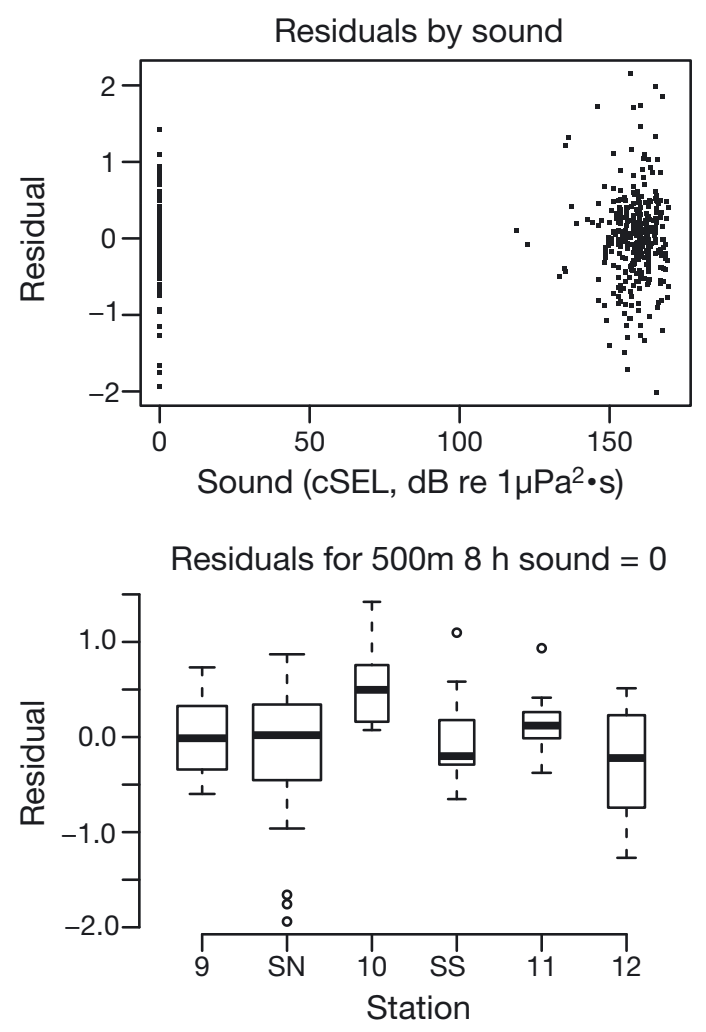

Fig. 7. Residual plots for final model with visibility, time, random effect for station and term for heterogeneity across stations. SN corresponds to Seismic North behaviour station and SS to the Seismic South behaviour station. Gray whale sightings at Stns 12 and 13 were pooled for analysis due to the small number of sightings at Stn 13. The width of the boxplot indicates sample size. Stations are shown in geographic order from north to south. The box shows the interquartile range (IQR) with the median value indicated by a horizontal line within the box. The whiskers (dotted lines) extend out to the smallest (largest) value within 1.5 times the IQR from the first (third) quartile. Outliers are shown as open circles

cial to test gray whale cues in the 1.2 to 0 reticle range to assess whether similar biases in distance estimation are present.

\section{Gray whale detection}

It is possible that reduction in detection probability at distances farther from observation stations also limited our ability to detect effects of sound. The detection function estimated using MRDS with our synchronized scan sightings indicated there was no decrease in detection probability with distance, visibility, sea state, or glare. However, swell height was found to slightly decrease detection probability. Previous work that estimated a shore-based detec- 
Distance by station: On/Off Sound

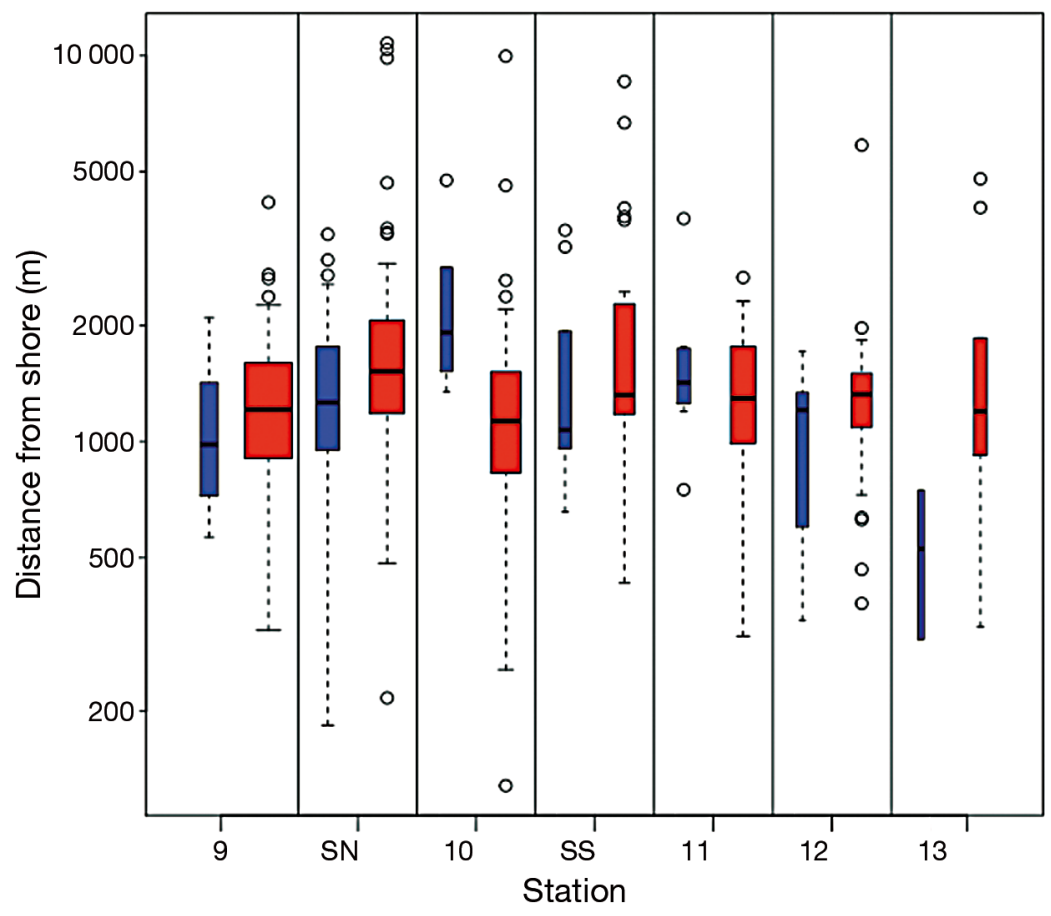

Fig. 8. Observed 'distance from shore' by station and by 'on' sound (red, i.e. during seismic survey activity) compared to 'off' sound (blue, in the pre-and post-seismic activity monitoring periods). Stns 9-13; SN: Seismic North behaviour station; SS: Seismic South behaviour station. The width of the boxplot indicates sample size (see Tables $2 \& 3$ ). Stations are shown in geographic order from north to south. The box shows the interquartile range (IQR), with the median value indicated by a horizontal line within the box. The whiskers (dotted lines) extend out to the smallest (largest) value within 1.5 times the IQR from the first (third) quartile. Outliers are shown as open circles make that sighting more detectable to a second observer. For example, we would expect that as visibility deteriorates, detection of whales at greater distances also deteriorates; this is supported by our finding in the regression analysis of shorter sighting distances from shore in poor visibility. The FI configuration also requires that all possible covariates affecting detection be included in the analysis; failure to do so results in positive bias in estimates of detection probability that increases with distance from the observer (Laake et al. 2011). While we included covariates (e.g. visibility, sea state) that are often found to negatively affect detection (Barlow 2006), it is unlikely that all possible covariates were available for our analysis. Therefore, it is possible that gray whale detection decreased to some degree with increasing distance from an observer. If SELs did result in whales moving farther from shore, as our data suggested, we would expect fewer sightings to be detected during scan surveys. This would result in negative bias in estimated sighting distance from shore and a reduced effect size, which may be why we found no significant effect of sound exposure on sighting distance from shore.

\section{Summary and conclusions}

tion function using a double-platform vessel and shore-based experiment also showed that gray whale detection did not decrease over distance within the tested $8 \mathrm{~km}$ radius of an observation station (E. Rexstad \& D. Borchers unpubl. data). Effects of environmental covariates on detection probability were not tested in the double-platform analysis due to small sample sizes. The MRDS analysis may also have been limited by small sample sizes that reduced statistical power to detect effects of both distance and environmental covariates on detection probability. In addition, the full independence (FI) MRDS configuration had to be used due to the density gradient of gray whales with respect to shore. The FI configuration estimates the detection function based solely on the proportion of sightings by each team that was seen by the other team. FI assumes that observers make detections independently, but it is unlikely that this assumption was satisfied because factors that make a gray whale sighting more detectable to one observer will likely also
To our knowledge, only Gailey et al. (2007a) have examined changes in sighting distance from shore by feeding baleen whales in response to sound exposure from seismic airguns; the seismic survey in this study was also conducted near the Piltun gray whale feeding area. Gailey et al. (2007a) found that the whales moved farther offshore in response to higher sound levels. Both Malme et al. (1984) and Clark et al. (1999) found that migrating gray whales exhibited avoidance of a moored airgun source located approximately $2 \mathrm{~km}$ offshore by increasing their distance from the source at the closest point of approach. In the Malme et al. (1984) study area, the migratory path was $\sim 2$ to $5 \mathrm{~km}$ from shore; thus, the airgun was located inshore of most whales. Migrating whales in the Clark et al. (1999) study area were generally closer to shore, and the moored airgun source was therefore centred within the migration corridor. Clark et al. (1999) additionally tested if whales 
showed an avoidance reaction to an airgun source moored $4 \mathrm{~km}$ from shore (i.e. offshore of most of the migrating whales); the majority of the whales did not adjust their path to avoid the source. Malme et al. (1984) also found that whales showed little response to an airgun source moving along 3 transects at 2.8, 5.5 and $15 \mathrm{~km}$ from shore. However, many other studies have noted an avoidance response, indicated by sighting marine mammals at increased distances from an active seismic source (e.g. McCauley et al. 2000, Stone \& Tasker 2006).

Malme et al. (1986) found that most feeding gray whales in open water that had been disturbed by seismic sound moved back to their original area and resumed feeding within approximately $1 \mathrm{~h}$ after the disturbance ceased. Our study examined sighting distance from shore with respect to cumulative sound levels over $8 \mathrm{~h}, 3 \mathrm{~d}$, and since the start of the seismic survey, and found no effects. It is possible that small shifts in gray whale distribution relative to shore occurred during periods of seismic activity, with subsequent recovery during line turns when airguns were silent. The longer time windows used in the analysis would have smoothed out this effect. Further work using short (e.g. $3 \mathrm{~h}$ ) sound accumulation periods, or comparing sighting distance from shore from scans conducted during seismic activity against times when airguns were silent, may provide further insight.

Our study suggests that there was a slight increase in sighting distance at most stations (median distance: $\sim 120 \mathrm{~m}$ ) during the seismic survey. However, this trend is neither statistically nor biologically significant. Such a shift would have little effect on gray whale foraging success in the Piltun feeding area, where highest densities of gray whales are typically between 1 and $3 \mathrm{~km}$ from shore (Vladimirov et al. 2011b). Our analysis suggests that the MMP was effective in mitigating displacement of gray whales with respect to shore in the feeding area. However, using sighting distance from shore as the indicator of response limited our ability to make inferences, because changes in gray whale abundance were not assessed, nor could this analysis determine whether a north-south (i.e. alongshore) shift in distribution occurred. These potential outcomes were assessed in our paper analyzing the effects of sound exposure on gray whale density surfaces (Muir et al. in press). That analysis suggested somewhat lower occupancy in areas with comparatively high sound exposure and associated slightly lower densities with higher sound exposure over the preceding 24 to $48 \mathrm{~h}$.
Acknowledgements. We thank R. Reeves, G. Donovan and 3 anonymous reviewers whose thoughtful comments and suggestions improved this manuscript. We are grateful to Doug Bell (Sakhalin Energy) for support during the development of the survey monitoring design and field protocols, and preliminary versions of the analyses. Richard Evans (Sakhalin Energy) also provided assistance during the analysis phases of this study. We appreciate the database support provided by Tony Mochizuki and the mapping assistance provided by Lucia Ferreira and Robin Tamasi (all of LGL Limited). Zizheng Li (JASCO Applied Sciences) assisted with calculations of seismic sound covariates and performed QA/QC of vessel positions. The ideas shared by and constructive discussions with members of the WGWAP Seismic Survey Task Force and Noise Task Force are gratefully acknowledged. We also thank the distribution field team members (P. Marchenko, D. Samarin, A. Samarina, M. Starodymova and A. Tishchuk) for their hard work and long hours spent conducting scan surveys. We are grateful to the behaviour team members who contributed scan data for analysis (A. Ermoshin, A. Filipiechev, A. Kalachev, D. Kovshov, I. Krupin, S. Piwetz and O. Sychenko). M. Austin, S. Borisov, D. Borovoy, V. Gritsenko, D. Kozel, V. Likhatchev, A. Rutenko, A. Soloviev, V. Sosnin, N. Tchichov, A. Tischuk, V. Uschipovsky and P. Zakharenko provided recorded and processed acoustic data. Peter Van-Der-Wolf and Roman Larin (Sakhalin Energy) and Igor Zhmaev (LGL Sakhalin) provided outstanding logistical assistance in the field. This study was funded by Sakhalin Energy Investment Company.

\section{LITERATURE CITED}

Austin ME, Chapman NR (2011) The use of tessellation in three dimensional parabolic equation modeling. J Comput Acoust 19:221-239

Barlow J (2006) Cetacean abundance in Hawaiian waters estimated from a summer/fall survey in 2002. Mar Mamm Sci 22:446-464

Bröker KC, Gailey G, Muir JE, Racca R (2015) Monitoring and impact mitigation during a $4 \mathrm{D}$ seismic survey near a population of gray whales off Sakhalin Island, Russia. Endang Species Res 28:187-208

Clark CW, Tyack P, Ellison WT (1999) Responses of four species of whales to sounds of SURTASS LFA sonar transmissions. Cornell University, Ithaca, NY, Woods Hole Oceanographic Institution, Woods Hole, MA, and Marine Acoustics, Arlington, VA. Available at: www. dtic.mil/cgi-bin/GetTRDoc?AD=ADA361300 (accessed 6 August 2013)

Coyle KO, Bluhm B, Konar B, Blanchard A, Highsmith RC (2007) Amphipod prey of gray whales in the northern Bering Sea: comparison of biomass and distribution between the 1980s and 2002-2003. Deep-Sea Res II 54: 2906-2918

> Dunham JS, Duffus DA (2001) Foraging patterns of gray whales in central Clayoquot Sound, British Columbia, Canada. Mar Ecol Prog Ser 223:299-310

Dunham JS, Duffus DA (2002) Diet of gray whales (Eschrichtius robustus) in Clayoquot Sound, British Columbia, Canada. Mar Mamm Sci 18:419-437

ESRI (Environmental Systems Research Institute) (2010) ArcGIS software products. ESRI, Redlands, CA

Fadeev VI (2013) Benthos studies in the feeding grounds of gray whales, 2012, Chap 3. In: Western (Okhotsk- 
Korean) gray whale monitoring program off the northeast coast of Sakhalin Island, 2012, Vol 2. Results and discussion. Final report for Exxon Neftegas Ltd. and Sakhalin Energy Investment Company Ltd., YuzhnoSakhalinsk, p 246-311. Available at: https://cmsdata. iucn.org/downloads/wgwap_13_8_wgw_research_and_ monitoring_program_in_2012__sakhalin_island__russia _volu.pdf (accessed 10 February 2014)

Gailey G (2008) Comparison of shore-based scan counts. Document WGWAP 5/18 presented to the Western Gray Whale Advisory Panel at its 5th meeting, 2-6 December 2008, Lausanne. Available at: http://cmsdata.iucn.org/ downloads/wgwap_5_doc_18_comparison_of_shore_ based_scan_counts.pdf (accessed 15 February 2013)

Gailey GA, Ortega-Ortiz J (2002) A note on a computerbased system for theodolite tracking of cetaceans. J Cetacean Res Manag 4:213-218

Gailey G, Würsig B, McDonald T (2007a) Abundance, behaviour, and movement patterns of western gray whales in relation to a 3-D seismic survey, Northeast Sakhalin Island, Russia. Environ Monit Assess 134:75-91

Gailey G, Sychenko O, Würsig B (2007b) Western gray whale behavior, movement, and occurrence patterns off Sakhalin Island, 2006. Report for LGL Ecological Research Associates Ltd., Exxon-Neftegas Ltd. and Sakhalin Energy Investment Company, Yuzhno-Sakhalinsk. Available at: www.sakhalinenergy.ru/media/d8ff2be2-8093481c-b581-bde59419d759.pdf (accessed 5 September 2013)

Gailey G, Sychenko O, Würsig B (2008) Patterns of western gray whale behavior, movement and occurrence off Sakhalin Island, 2007. Report for LGL Ecological Research Associates Ltd., Exxon-Neftegas Ltd. and Sakhalin Energy Investment Company, Yuzhno-Sakhalinsk. Available at: www.sakhalinenergy.ru/media/2a760f68ea52-4d66-a1cd-5951c7c4f88f.pdf (accessed 5 September 2013)

Gailey G, Sychenko O, Würsig B (2009) Patterns of western gray whale behavior, movement and occurrence off Sakhalin Island, 2008. Report for LGL Ecological Research Associates Ltd., Exxon-Neftegas Ltd. and Sakhalin Energy Investment Company, Yuzhno-Sakhalinsk. Available at: http://cmsdata.iucn.org/downloads/wgwap _6_13e_behaviour_monitoring_report_2008.pdf (accessed 5 September 2013)

Gailey G, Sychenko O, Würsig B (2010) Patterns of western gray whale behaviour, movement, and occurrence off Sakhalin Island, 2009. In: Western gray whale research and monitoring program in 2009, Sakhalin Island, Russia, Vol 2. Results and discussion. Report for Exxon Neftegas Ltd. and Sakhalin Energy Investment Company Ltd., Yuzhno-Sakhalinsk, p 298-365. Available at: http://cmsdata.iucn.org/downloads/wgwap_8_doc_11_seic _wgw_program_annual_report_2009_volume_ii_ results_and_discussion.pdf (accessed 5 September 2013)

Gailey G, Sychenko O, Würsig B (2011a) Patterns of western gray whale behavior, movement, and occurrence off Sakhalin Island, 2010, Chap 5. In: Western gray whale research and monitoring program in 2010, Sakhalin Island, Russia, Vol I. Background and methods. Report for Exxon Neftegas Ltd. and Sakhalin Energy Investment Company Ltd., Yuzhno-Sakhalinsk, p 126-144. Available at: http://cmsdata.iucn.org/downloads/wgwap_10_ doc_12_2010_mnr_report_volume_i_methods__eng__ 29_apr.pdf (accessed 5 September 2013)
Gailey G, Sychenko O, Würsig B (2011b) Patterns of western gray whale behavior, movement, and occurrence off Sakhalin Island, 2010, Chap 4. In: Western gray whale research and monitoring program in 2010, Sakhalin Island, Russia, Vol 2. Results and discussion. Report for Exxon Neftegas Ltd. and Sakhalin Energy Investment Company Ltd., Yuzhno-Sakhalinsk, p 286-348. Available at: http://cmsdata.iucn.org/downloads/wgwap_10_ doc_14_2010_mnr_report_volume_ii_results__eng___ reducedsize.pdf (accessed 5 September 2013)

Gordon J, Gillespie D, Potter J, Frantzis A and others (2003) A review of the effects of seismic survey on marine mammals. Mar Technol Soc J 37:16-34

Hildebrand JA (2009) Anthropogenic and natural sources of ambient noise in the ocean. Mar Ecol Prog Ser 395:5-20

Kinzey D, Gerrodette T (2003) Distance measurements using binoculars from ships at sea: accuracy, precisions and effects of refraction. J Cetacean Res Manag 5: 159-171

Laake J, Borchers D (2004) Methods for incomplete detection at distance zero. In: Buckland ST, Anderson DR, Burnham KP, Laake JL, Borchers DL, Thomas L (eds) Advanced distance sampling: estimating abundance of biological populations. Oxford University Press, Oxford, p 108-189

Laake JL, Collier BA, Morrison ML, Wilkins RN (2011) Point-based mark-recapture distance sampling. J Agric Biol Environ Stat 16:389-408

Leaper R, Gordon J (2001) Application of photogrammetric methods for locating and tracking cetacean movements at sea. J Cetacean Res Manag 3:131-141

Leaper R, Burt L, Gillespie D, MacLeod K (2010) Comparisons of measured and estimated distances and angles from sightings surveys. J Cetacean Res Manag 11: 229-237

Lerczak JA, Hobbs RC (1998) Calculating sighting distances from angular readings during shipboard, aerial, and shore-based marine mammal surveys. Mar Mamm Sci 14:590-599

LGL (2010) Environmental impact assessment of Sakhalin Energy Investment Company's 3-D seismic programme in the Piltun-Astokh Area, Sakhalin Island, Russia. Report for Sakhalin Energy Investment Company, Ltd., Yuzhno-Sakhalinsk. Available at: www.sakhalinenergy. ru/media/87cb2a5c-7946-4993-a173-d5101045cfae.pdf (accessed 1 February 2015)

Malme CI, Miles PR, Clark CW, Tyack P, Bird JE (1984) Investigations of the potential effects of underwater noise from petroleum industry activities on migrating gray whale behavior/Phase II: January 1984 migration. Report for US Department of the Interior, Minerals Management Service, Alaska OCS Office, Anchorage, AK. Available at: www.boem.gov/BOEM-Newsroom/ Library/Publications/1983/rpt5586.aspx (accessed 5 February 2013)

Malme CI, Würsig B, Bird JE, Tyack P (1986) Behavioral responses of gray whales to industrial noise: feeding observations and predictive modeling. Outer Continental Shelf Environmental Assessment Program, US Dept. of Commerce, NOAA, OCSEAP Final Rep 56:393-600. Available at: www.arlis.org/docs/vol1/OCSEAP2/Final/ 12824468/F\%20v56.pdf (accessed 25 November 2015)

McCauley RD, Fewtrell J, Duncan AJ, Jenner C and others (2000) Marine seismic surveys-a study of environmental implications. APPEA J 40:692-708 
Muir JE, Ainsworth LM, Racca R, Bychkov Y and others (in press) Gray whale densities during a seismic survey off Sakhalin Island, Russia. Endang Species Res, doi: 10.3354/esr00709

Muir JE, Joy R, Bychkov Y, Bröker K and others (2015) Delineation of a coastal gray whale feeding area using opportunistic and systematic survey effort. Endang Species Res 29:147-160

Nakagawa N, Schielzeth H (2013) A general and simple method for obtaining $\mathrm{R}^{2}$ from generalized linear mixedeffects models. Methods Ecol Evol 4:133-142

Nerini MK (1984) A review of gray whale feeding ecology. In: Jones ML, Swartz S, Leatherwood S (eds) The gray whale. Academic Press, Orlando, FL, p 423-450

Nowacek DP, Thorne LH, Johnston DW, Tyack PL (2007) Responses of cetaceans to anthropogenic noise. Mammal Rev 37:81-115

Pinheiro JC, Bates DM (2000) Mixed effects models in S and S-Plus. Springer Verlag, New York, NY

R Development Core Team (2012) R: a language and environment for statistical computing. R Foundation for Statistical Computing, Vienna. Available at: www.r-project.org

R Development Core Team (2014) R: a language and environment for statistical computing. R Foundation for Statistical Computing, Vienna, AT. Available at: www. r-project.org

Racca R, Austin M, Rutenko A, Bröker K (2015) Monitoring the gray whale sound exposure mitigation zone and estimating acoustic transmission during a 4-D seismic survey, Sakhalin Island, Russia. Endang Species Res 29: 131-146

Richardson WJ, Greene CR Jr, Malme CI, Thomson DH (1995) Marine mammals and noise. Academic Press, San Diego, CA

Southall BL, Bowles AE, Ellison WT, Finneran JJ and others (2007) Marine mammal noise exposure criteria: initial scientific recommendations. Aquat Mamm 33:411-522

Stone CJ, Tasker ML (2006) The effects of seismic airguns on cetaceans in UK waters. J Cetacean Res Manage 8: 255-263

Tyack P (2009) Acoustic playback experiments to study behavioural responses of free-ranging marine animals to anthropogenic sound. Mar Ecol Prog Ser 395:187-200

Vladimirov VA, Starodymov SP, Muir JE, Bychkov YA (2010) Western gray whale distribution surveys (vessel-based and onshore): introduction and methods. Final Report by the All-Russian Research Institute of Fisheries and Oceanography (VNIRO), Moscow, Chap 2. In: Western

Editorial responsibility: Randall Reeves, Hudson, Quebec, Canada; Greg Donovan, Cambridge, UK gray whale research and monitoring program in 2009, Sakhalin Island, Russia, Vol 1. Background and methods. Report for Exxon Neftegas Ltd. and Sakhalin Energy Investment Company Ltd., Yuzhno-Sakhalinsk, p 29-59. Available at: http://cmsdata.iucn.org/downloads/ wgwap_8_doc_10_seic_wgw_program__annual_report _2009_volume_i_background_and_methods_.pdf (accessed 1 February 2015)

Vladimirov VA, Starodymov SP, Muir JE, Bychkov YA (2011a) Western gray whale distribution surveys (vesselbased and onshore): introduction and methods. Final Report by the All-Russian Research Institute of Fisheries and Oceanography (VNIRO), Moscow, Chap 2. In: Western gray whale research and monitoring program in 2010, Sakhalin Island, Russia, Vol 1. Background and methods. Report for Exxon Neftegas Ltd. and Sakhalin Energy Investment Company Ltd., Yuzhno-Sakhalinsk, p 34-62. Available at: http://cmsdata.iucn.org/downloads/ wgwap_10_doc_12_2010_mnr_report_volume_i_methods _eng__29_apr.pdf (accessed 5 September 2013)

Vladimirov VA, Starodymov SP, Kalachev AV (2011b) Distribution and abundance of western gray whales off northeast Sakhalin Island, August-September 2010 (based on data from onshore and vessel-based surveys). Final Report by the All-Russian Research Institute of Fisheries and Oceanography (VNIRO), Moscow, Chap 1. In: Western gray whale research and monitoring program in 2010, Sakhalin Island, Russia, Vol 2. Results and discussion. Report for Exxon Neftegas Ltd. and Sakhalin Energy Investment Company Ltd., Yuzhno-Sakhalinsk, p 10-105. Available at: http://cmsdata.iucn.org/downloads/wgwap _10_doc_14_2010_mnr_report_volume_ii_results__eng__ reducedsize.pdf (accessed 5 September 2013)

Wartzok D, Popper AN, Gordon J, Merrill J (2003) Factors affecting the responses of marine mammals to acoustic disturbance. Mar Technol Soc J 37:6-15

Williams R, Leaper R, Zerbini AN, Hammond PS (2007) Methods for investigating measurement error in cetacean line-transect surveys. J Mar Biol Assoc UK 87: 313-320

Würsig B, Cipriano F, Würsig M (1991) Dolphin movement patterns: information from radio and theodolite tracking studies. In: Pryor K, Norris KS (eds) Dolphin societies discoveries and puzzles. University of California Press, Los Angeles, CA, p 79-112

Zuur AF, Ieno EN, Walker NJ, Saveliev AA, Smith GM (2010) Mixed effects models and extensions in ecology with R. Springer, New York, NY

Submitted: January 3, 2014; Accepted: September 24, 2015 Proofs received from author(s): December 3, 2015 